\title{
Dual-Beam Microscopy Reveals Details of the Activated Cells of the Stromal Bone Marrow
}

\author{
Ana Paula R. Abud ${ }^{1}$; Ediely L. O. Coletto ${ }^{1}$; Simone M. de Oliveira ${ }^{1}$; Diogo Kuczera ${ }^{1}$; \\ David Wall ${ }^{2}$; Ben Lich ${ }^{2}$; Ruth J. G. Schadeck ${ }^{1}$; Edvaldo S. Trindade ${ }^{1}$; Dorly de Freitas \\ Buchi $^{1}$ \\ ${ }^{1}$ Laboratório de Estudos de Células Inflamatórias e Neoplásicas, Departamento de \\ Biologia Celular, SCB, Universidade Federal do Parana (UFPR), Curitiba, PR, Brazil, \\ and ${ }^{2}$ FEI Company, Acht, 5651 GG, Eindhoven, The Netherlands.
}

The bone marrow microenvironment includes growth factors, stromal cells, the extracellular matrix, and progenitor cells that differentiate into mature blood cells. A complex matrix from Calcarea carbonica, containing particular associations at a 10$20 \%(\mathrm{w} / \mathrm{v})$ concentration of each relevant compound (laboratory designation: M8), was applied to cultures of bone marrow cells. Cells were incubated for $96 \mathrm{~h}$. It was observed that adherent cells were more numerous, larger, and morphologically activated compared with control cells, and exhibited macrophage characteristics. Treated cells showed characteristics indicative of activation and showed more cell niches associated with adherent cells, suggesting increased proliferation and differentiation. These activated stromal cells were examined by dual-beam microscopy, a variant of scanning electron microscopy. This microscopy is an alternative to the serial section transmission electron microscopy approach for imaging of cells and tissue ${ }^{[1,2]}$. The technique reveals details inside activated cells. This form of electron microscopy uses a focused ion beam (FIB) to cut at a designated site in the specimen, followed by an examination of the newly generated surface using a scanning electron beam. Reiterations of these steps yield a series of surface maps of the specimen, which can be computationally assembled into a threedimensional (3D) volume representation ${ }^{[1]}$. Thus, in the present study, we used this technology to observe activated stromal bone marrow cells, and obtain serial images at a resolution adequate to allow visualization of all relevant organelles, including the nucleus, the Golgi complex, the endoplasmic reticulum, and secretion vesicles. The results indicate that activated cells vigorously secrete both proteins and carbohydrates, which may stimulate other cells, independent of gap junctions. These results indicate that treatment with M8 causes stroma cells to upregulate secretory mechanisms for proteins and carbohydrates (glycoproteins and/or proteoglycans), which could act as signaling molecules responsible for the observed increase in cell niches.

\section{References:}

[1] J. A. Heymann et al., J Struct Biol, 155 (2006) 63.

[2] G. Knott et al., J Neurosci, 28 (2008) 2959. 

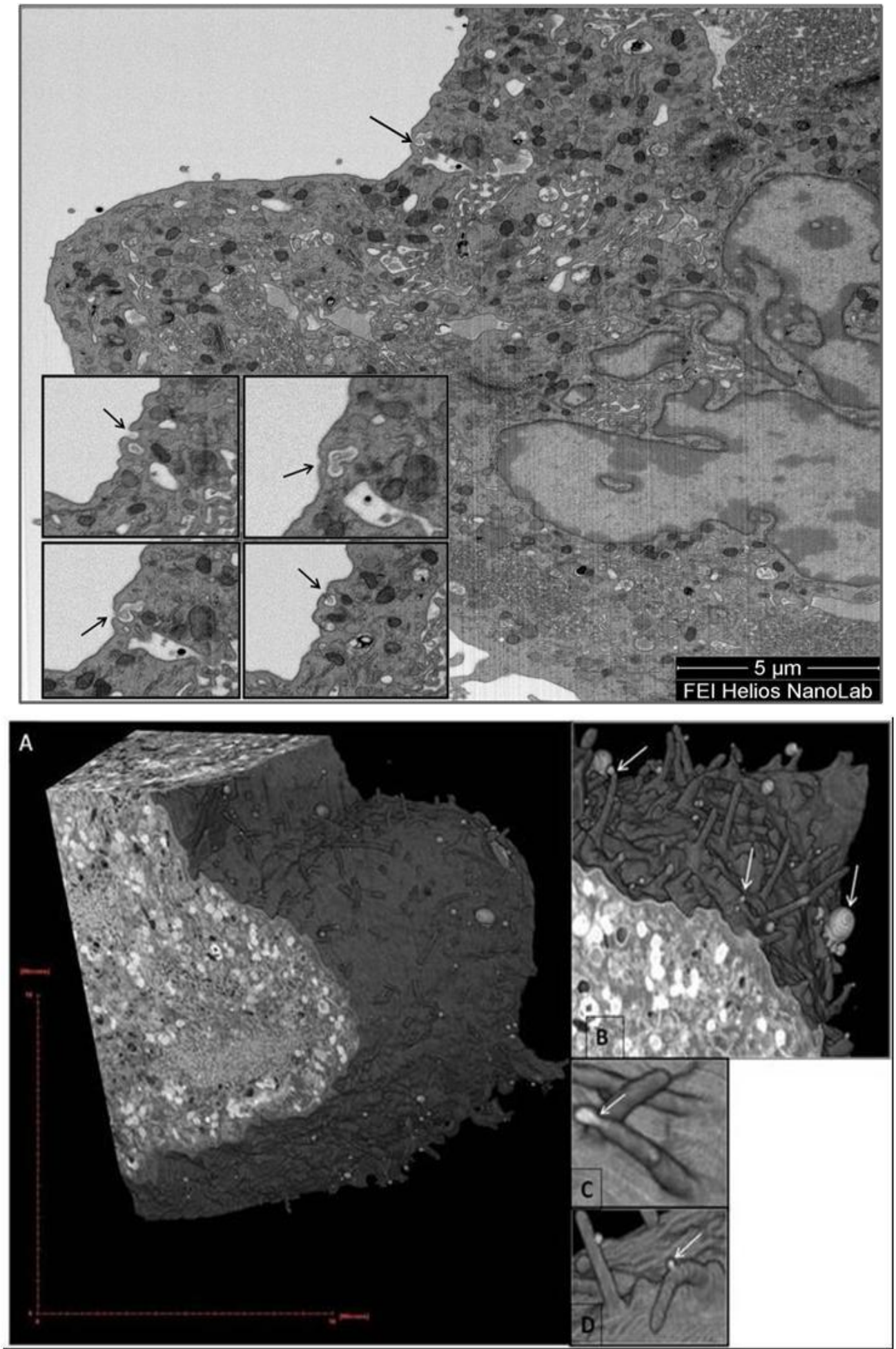

Figure 1: A stroma-adherent bone marrow cell after serial section scanning electron microscopy. This permits all relevant organelles, and secretion vesicles (arrows), to be observed. Such structures were examined serially (being detached in only 4 of 214 slices), and this showed that the cell secretes a structure surrounded by a membrane, reflecting expulsion of internal vesicles or exosomes. Figure 2: Large datasets acquired using dual beam methodology were employed for reconstruction and analysis of 3D images. Here, a negative image of the surface of bone marrow stromal secretor cells shows many projections and small vesicles containing electron-dense material budding from the plasma membrane (arrows) (A-D). The shedding of vesicles is preceded by the budding of small cytoplasmic protrusions, which next detach by fission of stalks (details in $\mathrm{C}$ and $\mathrm{D}$ ).exosomes. The insets allow this process to be better understood. 